\title{
Manejo socioambiental da cana-de-açúcar e produção de rapadura na comunidade de Varginha, em Santo Antônio de Leverger, MT, Brasil
}

Sugarcane social-environmental management and brown sugar production in Varginha, community in Santo Antônio de Leverger, MT, Brazil

\section{La gestion sociale et environnementale de canne à sucre et la production de cassonade dans la communauté Varginha, à Santo Antônio de Leverger, MT, Brésil}

\author{
Gestión socio-ambiental de la caña de azúcar y la producción de panela en la \\ comunidad de Varginha, en Santo Antônio de Leverger, MT, Brasil \\ Bruno da Silva Barbosa* \\ (bruno-02@hotmail.com) \\ Carla Maria Abido Valentini* \\ (carla.valentini@blv.ifmt.edu.br) \\ Rozilaine Aparecida Pelegrine Gomes de Faria* \\ (rozilaine.faria@blv.ifmt.edu.br)
}

Recebido em 25/09/2015; revisado e aprovado em 23/11/2015; aceito em 30/03/2016

DOI: http:/ / dx.doi.org/10.20435/1984-042X-2016-v.17-n.3(03)

\begin{abstract}
Resumo: Objetivou-se pesquisar o manejo socioambiental da cana-de-açúcar e a produção de rapadura na comunidade ribeirinha de Varginha, em Santo Antônio de Leverger, MT. Foram utilizadas entrevistas semiestruturadas com questões abertas e observação direta para o tratamento descritivo. No único engenho ainda existente no local, quatro irmãos trabalham de forma consorciada, usando o conhecimento que aprenderam com seus antepassados.
\end{abstract}

Palavras-chave: cultura ribeirinha; engenhos de cana-de-açúcar; produção de rapaduras.

Abstract: The objective was to find the social and environmental management of sugarcane and brown sugar production in the riverside community of Varginha, in Santo Antônio de Leverger, MT, Brazil. We used semi-structured interviews with open questions and direct observation for the descriptive treatment. In the only remaining mill on site, four brothers work in consortium using the knowledge they have learned from their ancestors.

Key words: riverside culture, mills of cane sugar, brown sugar production.

Résumé: L'objectif était de trouver la gestion sociale et environnementale de la canne à sucre et la production de cassonade dans la communauté fluviale de Varginha, à Santo Antônio de Leverger, MT, Brésil. Nous avons utilisé des entretiens semi-structurés avec des questions ouvertes et l'observation directe pour le traitement descriptif. Dans le moulin ne reste dans la région, quatre frères travaillent en consortium et ils utilisent les connaissances qu'ils ont appris de leurs ancêtres. Mots-clés: riviere culture, mills de sucre de canne, la production de sucre brun.

Resumen: El objetivo era encontrar la gestión social y ambiental de la caña de azúcar y de la producción de panela a partir de la melaza de caña de azúcar en la comunidad ribereña de Varginha, en Santo Antônio de Leverger, MT, Brasil. El tratamiento descriptiva se utilizó herramientas metodológicas tales como entrevistas abiertas semiestructuradas y observación directa. El único molino que queda en el lugar, cuatro hermanos que trabajan en forma consorcio utilizando los conocimientos que han aprendido de sus antepasados.

Palabras clave: cultura ribereña; molinos de caña de azúcar; producción de panela.

\footnotetext{
* Instituto Federal de Ensino, Ciência e Tecnologia de Mato Grosso (IFMT), Cuiabá, Mato Grosso, Brasil.
} 


\section{INTRODUÇÃO}

A cana-de-açúcar (Saccharum officinarum L.) é uma planta que apresenta elevada importância econômica. Além de ser de fácil manejo, seu produto (caldo) e subproduto (bagaço) são utilizados como matéria-prima para produção de cachaça, rapadura, açúcar, etanol, energia elétrica, ração animal e adubo (MACEDO, 2008).

Ao longo da História, para romper com o monopólio da produção de açúcar exercido pelo Oriente Médio, os portugueses encontraram no Brasil Colônia uma alternativa para ingressarem definitivamente nesse mercado e estimularem seu crescimento econômico (BRAIBANTE et al., 2013). As primeiras mudas de cana-de-açúcar plantadas no Brasil foram trazidas da Ilha da Madeira, em Portugal, no século XVI por Martim Afonso de Souza, em 1532 (BERNARDES; CÂMARA, 2001).

Vários foram os motivos para a escolha da cana-de-açúcar, entre eles, a existência no Brasil do solo de massapé, que é um tipo de solo de cor bem escura e fértil, encontrado na região litorânea do nordeste brasileiro. Os produtos da cana-de-açúcar foram, portanto, um alicerce econômico da colonização portuguesa no Brasil entre os séculos XVI e XVII (RODRIGUES, 2010).

Em 1600, a Colônia portuguesa contava com ao menos 120 engenhos, distribuídos pelas capitanias do litoral, principalmente Pernambuco, Bahia e São Vicente (PÓVOAS, 2000). Para Furtado (2003), a grande expansão do mercado do açúcar, na segunda metade do século XVI, constitui um fator fundamental do êxito da colonização do Brasil.

A fabricação da rapadura, que se iniciou nas Ilhas Canárias, possivelmente no século XVI, constituiu-se uma solução prática de transporte de alimento em pequena quantidade para uso individual. A rapadura começou a ser produzida no Brasil principalmente na região Nordeste, onde se encontrava instalada a maior par- te dos engenhos de todo o Brasil. O produto, feito de mel de engenho dado certo ponto, algumas vezes também chamado de "raspadura" (originada do verbo raspar), originou-se da raspagem das camadas espessas de açúcar presas às paredes dos tachos utilizados para a fabricação do produto, e depois moldadas em fôrmas semelhantes às de tijolos (OLIVEIRA; NASCIMENTO; BRITTO, 2007).

Segundo o último Censo Agropecuário da Indústria Canavieira (IBGE, 1995-1996), a produção de rapadura na Região Centro-Oeste foi de 5,75\%. O estado de Goiás foi o maior produtor da região com 3,99\%, seguido de Mato Grosso, que aparece em segundo lugar com uma produção de $1,22 \%$. Depois, Mato Grosso do Sul com 0,50\% e, por fim, Distrito Federal com 0,03\%.

Fatos históricos descritos por Póvoas (2000) envolvendo a cana-de-açúcar mostram o forte desempenho econômico, social e político envolvendo a indústria açucareira que movimentou o estado de Mato Grosso no final das décadas do século XIX até meados do século XX. Com a fertilidade da terra, era comum encontrar plantações de cana-de-açúcar nas margens do rio Cuiabá, pois, após receberem os nutrientes necessários para o seu desenvolvimento provenientes de enchentes, essas áreas permaneciam propícias para esse tipo de cultivo.

Dessa forma, os engenhos e usinas se proliferaram às margens do rio Cuiabá graças à via fluvial, que pôde trazer as maquinarias modernas da Europa, e aos trabalhadores, primeiramente escravos, e que, mesmo após a abolição da escravatura, ainda continuaram a receber um tratamento escravista dos proprietários conhecidos como "coronéis" (SIQUEIRA; COSTA; CARVALHO, 1989).

Assim, essa era uma opção para muitos, que deixavam suas famílias em busca de uma renda para sua sobrevivência. Como nem sempre a quantidade plantada no canavial das usinas era suficiente 
para atender as demandas dos engenhos, muitas comunidades ribeirinhas fizeram do fornecimento de cana-de açúcar para as usinas parte do seu sustento. Porém parte da produção da matéria-prima oriunda das atividades ribeirinhas era transformada em produtos artesanais de maior durabilidade, a exemplo da cana-de-açúcar que era transformada em açúcar denominado "potó", escuro ou mascavo e rapadura (SIQUEIRA; COSTA; CARVALHO, 1989; SILVA; MARTA, 2011).

As comunidades rurais, que ainda mantêm práticas e conhecimentos locais às margens da agricultura moderna, representam um importante contraponto na contemporaneidade e desempenham um papel imprescindível na produção e diversificação de alimentos, na conservação dos recursos genéticos das plantas cultivadas e, consequentemente, na promoção da segurança alimentar (AMOROZO et al., 2008).

Na comunidade de Varginha, situada no município de Santo Antônio de Leverger, MT, a pesca sempre foi uma das atividades principais dos ribeirinhos e, com o passar do tempo, começaram a plantação da cana-de-açúcar. Assim, a produção da rapadura vem sendo repassada pelos seus ascendentes, garantindo, a esse grupo, a continuidade dos saberes e conhecimento do ambiente.

Atualmente, a produção de rapadura em Mato Grosso tem se limitado aos engenhos existentes e remanescentes em comunidades tradicionais, à beira do Rio Cuiabá, a exemplo de Varginha. Com o intuito de observar a atividade no engenho ribeirinho, o objetivo deste trabalho foi pesquisar o manejo socioambiental da cana-de-açúcar e a produção de rapadura na comunidade ribeirinha de Varginha, em Santo Antônio de Leverger, MT.

\section{MATERIAL E MÉTODOS}

A Baixada Cuiabana abrange uma área territorial de 85.369,70 km². É constituída pelos municípios Cuiabá, Várzea Grande, Nossa Senhora do Livramento, Santo Antônio de Leverger, Acorizal, Barão de Melgaço, Chapada dos Guimarães, Jangada, Nobres, Nova Brasilândia, Planalto da Serra, Poconé e Rosário Oeste. Essas localidades pertencem à bacia dos rios Cuiabá e Paraguai e têm, como principal polo de desenvolvimento e raízes socioculturais, a cidade de Cuiabá (ANDRADE; RIBEIRO, 2012).

A comunidade de Varginha encontra-se à margem esquerda do rio Cuiabá (UTM: E 596.353 m - N 8.251.432 m), e está situada no Município de Santo Antônio de Leverger, estado de Mato Grosso, a 7 $\mathrm{km}$ da sede (Santo Antônio de Leverger), e $22 \mathrm{~km}$ da capital (Cuiabá). Pela Lei n. 4200, de 16 de junho de 1980, publicada no Diário Oficial do mesmo dia, foi criado o Distrito de Varginha no município de Santo Antônio de Leverger. A comunidade fica próxima ao Rio Cuiabá, mas fora do alcance das águas no período de cheia do rio (GUARIM, 2005).

De acordo com a classificação climática de Köppen, a Baixada Cuiabana é caracterizada pelo clima tropical semiúmido $(\mathrm{Aw})$, com duas estações bem definidas, uma seca (outono-inverno) e outra chuvosa (primavera-verão). As médias anuais térmica e pluviométrica são de aproximadamente $26,5^{\circ} \mathrm{C}$ e $1.420 \mathrm{~mm}$, respectivamente, com regime de chuva sazonal e período seco com duração de maio a setembro (MAITELLI, 1994).

Sua distribuição espacial é semicircular, tendo em seu centro um vasto espaço aberto, em que se localizam três campos de futebol. Ao redor do centro "comum", ficam as casas - muitas sem muros, onde se agrupam famílias -, e uma rua de paralelepípedos, cujo nome é Rua Bom Jesus, padroeiro da comunidade, que serve de caminho para o trânsito dos mo- 
radores e dos carros. Ao redor, além das casas, existe a escola, a igreja, um galpão de festas, dois mercados e vários bares (PRADO; OSÓRIO, 2011). É uma região agrícola perfeitamente urbanizada com seu calçamento, asfalto, energia elétrica, água, telefonia móvel, internet-ainda que precária (PINTO, 2014).

Os dados foram coletados nos meses de abril e maio de 2015, no único engenho da comunidade de Varginha, "Engenho dos França", localizado à margem direita do rio Cuiabá, a $3 \mathrm{~km}$ da rua principal da comunidade, por meio de observação in loco e utilizando a técnica de entrevistas semiestruturadas (ALBUQUERQUE et al., 2008). As questões foram abertas e abordaram tanto os aspectos sociais da comunidade e do informante, quanto as questões relacionadas aos tratos culturais e ambientais do manejo da cana-de-açúcar e produção de rapadura no engenho.

As perguntas a que responderam os produtores/rapadureiros foram transcritas ao longo do trabalho, além de registros de áudio e imagem, com a devida autorização do entrevistado por meio de um Termo de Anuência Prévia, Livre e Esclarecido.

\section{RESULTADOS E DISCUSSÃO}

A comunidade de Varginha tem mais de 100 anos de fundação, mas, de acordo com a Lei Estadual n. 4200 de 16 de junho de 1980, a sua criação como Distrito data de 35 anos.

O estudo realizado em campo buscou acompanhar e registrar in loco a produção da rapadura no "Engenho dos França", que funciona na comunidade há mais de 50 anos e é o único em atividade de segunda a sábado nos dias de hoje.

Aprendizado passado de pai para filhos há gerações, de acordo com Amorozo (2002), o cultivo em comunidades agrícolas tradicionais é algo que se aprende muito cedo, à medida que as crianças acompanham os adultos às roças. Essa herança no aprendizado envolve o saber fazer e o saber cuidar do ambiente que os cercam. O saber que dominam sobre o meio físico e biológico onde estão inseridos é fundamental para o planejamento de estratégias de conservação (FERREIRA, 1999).

Hoje em dia trabalham no engenho quatro irmãos, todos nascidos na comunidade de Varginha, sendo eles: dona Juvelina, 73 anos, Sr. Francisco, 78 anos, Sr. Brasílio, 76 anos e Sr. Antonio de 69 anos. Todos começaram a trabalhar desde 10 anos de idade, são casados e estudaram até a $4^{\text {a }}$ serie do antigo ensino primário na escola local, correspondente ao $5^{\circ}$ ano do estudo fundamental. Os quatro irmãos se intercalam, de segunda a sábado, nos trabalhos do engenho na época do corte da cana-de-açúcar. As formas cooperativas de trabalho são sempre praticadas em comunidades, principalmente nas ribeirinhas, conforme enfatizado por Guarim (2005), e assim acontece nas comunidades do rio Cuiabá, em Santo Antônio de Leverger.

Uma característica apontada por Diegues (1996) é de que, nas comunidades tradicionais, o conhecimento é transferido de geração em geração por via oral, assim como a noção de território ou espaço onde esses grupos sociais se reproduzem econômica e socialmente. Porém, assim como outros grupos, por exemplo, os "chacareiros" e visitantes de final de semana, que não compartilham dos mesmos traços culturais da comunidade (PRADO; OSÓRIO, 2011), os ribeirinhos tiveram que se adaptar às leis que os disciplinam. Esses "chacareiros", em geral, são pessoas de fora da comunidade que compraram os imóveis e os transformaram em áreas de lazer, como observado por Guarim (2005).

Dona Juvelina abordou duas questões importantes sobre isso. A primeira foi o fato de como era realizada a coleta e transporte de água para as casas. A segunda, de que eles, como pertencentes às comunidades ribeirinhas, também tiveram que se enquadrar na Lei n. 12.651 de 25 
de maio de 2012, Novo Código Florestal, que dispõe sobre a proteção da vegetação nativa e que proíbe a plantação e a criação de animais à beira do Rio Cuiabá:

Era tão gostoso, porque aqui não tinha água encanada, e nem a luz elétrica não tinha... então quando chegada na época da seca, a dificudade é por causa da água né... nois trazia a água do rio na cabeça, aí tudo ia morá na chácara, lá na beira do rio, porque lá a gente levava os porcos tomar água... nois fazia plantação de lavoura na beira do barranco, hortalice, batata, mandioca, tomate, alho, cebola, a gente plantava, lugar baum, porque é beira de barranco é terra boa e agora não pode mais... proibido. (D. Juvelina, 73 anos).

A largura do rio Cuiabá é, em média, 150 metros, e a Lei supracitada define que para os cursos de água de largura variando entre 50 e 200 metros, as bordas devem ter largura mínima de 100 metros para a proteção da vegetação nativa. Para o morador da beira do rio, terra e água são partes indissociáveis à manutenção de sua vida (FERREIRA, 1999). A sua percepção revela a perspectiva local para aspectos fundamentais do desenvolvimento, em contraste com a visão dos gestores públicos (CONTERATO et al., 2012). Para ele, o espaço rural está associado à idéia central de que o território possui um tecido social, que vai muito além de seus atributos naturais, com raízes históricas, configurações políticas e identidades que desempenham um papel ainda pouco conhecido no próprio desenvolvimento econômico (ABRAMOVAY, 2001). Assim, fazê-los adaptar às regras de quem não respeita os ciclos naturais e os recursos naturais renováveis afeta sua cultura, repassada por seus ancestrais, como o costume de ter suas roças à beira do rio.

\section{CANAVIAL}

A lavoura de cana-de-açúcar é uma atividade agrícola classificada como semipermanente, que se exaure ao longo de vários anos de produção. A longevidade do canavial decorre basicamente das características biológicas das variedades plantadas, dos nutrientes do solo e das condições edafoclimáticas. A capacidade de rebrota da planta possibilita vários cortes, porém, a cada corte, a produtividade da cana decresce (MAULE; MAZZA; MARTHA JR., 2001; BORBA; BAZZO, 2009).

O canavial da família França (Figura 1A) tem mais de $1.000 \mathrm{~m}^{2}$ de plantação, e a cana-de-açúcar plantada é do tipo "paranaense", nome este denominado pela comunidade local. $\mathrm{O}$ espaçamento entre os indivíduos da plantação de cana-de-açúcar no canavial é de 0,3 a 0,5m, que segundo Sr. Francisco (73 anos), esposo de D. Juvelina, facilita na hora do corte. É a D. Juvelina quem sempre trabalha com seu esposo nas atividades do engenho.

Siqueira, Costa e Carvalho (1989) citaram como cana-de-açúcar usualmente plantada à beira do rio Cuiabá a caiana, a rosa, a cristalina e até a roxa originária da Bolívia. Porém, tanto em Varginha como na comunidade ribeirinha de Bonsucesso, em Várzea Grande, MT, eles denominam a variedade de paranaense. Ferreira (2010) ressalta que, como o cultivo da cana-de-açúcar está na área há mais de um século, as lavouras representam importantes bancos de conservação de germoplasmas e que as variedades existentes nos canaviais adquiriram adaptabilidade às pragas e enchentes. A diversidade biológica, portanto, é também fruto de uma construção cultural e social. As espécies são objetos de conhecimento, de domesticação e uso, fonte de inspiração para mitos e rituais das sociedades tradicionais e, finalmente, mercadoria nas sociedades modernas (DIEGUES et al., 2000).

No entanto, o adensamento da cultura no campo pode comprometer a 
produtividade. Segundo Townsend (2000) recomenda-se que a cana-de-açúcar tenha um espaçamento entre plantas de 0,9 a $1,4 \mathrm{~m}$. Quanto mais adensado for o plantio, menor será o diâmetro dos colmos e menor será a produtividade do caldo. Contudo as comunidades reproduzem o que aprenderam com seus ancestrais, e não normas técnicas. A Convenção da Diversidade Biológica (CDB) assinada em 1992, ratificada em 1994 e promulgada em 1998 no Brasil, expressa claramente a compreensão de que muitas comunidades locais e populações indígenas com estilos de vida tradicionais não apenas dependem dos recursos biológicos, mas possuem conhecimentos, inovações e práticas que são relevantes tanto à conservação da diversidade biológica quando à utilização sustentável de seus componentes (MENDES; COSTA FILHO; SANTOS, 2015).

O canavial é todo cercado com telas para protegê-lo dos animais que se alimentam da cana-de-açúcar. A distância do canavial ao engenho é de $50 \mathrm{~m}$ e, do canavial à margem do rio, mais de $100 \mathrm{~m}$, como prevê a Lei 12.651 de 25 de maio de 2012. De acordo com a Lei supracitada e sob a fiscalização dos órgãos competentes, também não se pode mais expandir o canavial para perto do engenho ou do rio Cuiabá, o que é percebido pela comunidade como uma ação de impedimento e dificuldade para manter o cultivo de espécies para sua sobrevivência. É importante ressaltar que, do patrimônio ambiental representado pelo rio, a mata, $\mathrm{o}$ solo e os recursos nele contidos, depende o patrimônio humano que carrega uma diversidade cultural relacionada com a biodiversidade da área (FERREIRA, 1999). As consequências dessas drásticas mudanças para uma comunidade que garante seu sustento e reproduz sua cultura a partir da terra são amplas e profundas, pois o espaço rural é um território que se inclina sobre o sentido de enraizamento, $\mathrm{o}$ sentimento de pertencimento em relação aos laços afetivos e morais que tecem com o solo onde nasceram e onde estão sepultados seus antepassados (CLAVAL, 1996).

D. Juvelina falou sobre a questão do plantio com a mão de obra familiar no canavial, do tempo do canavial e da proteção da plantação contra os animais silvestres e domésticos que se alimentam da cana-de-açúcar:

O canaviá tem uma parte de um
irmão, aí tem de otro, aí tem o
nosso, aí tem de otro irmão, onde
achava espaço plantava otro...
que não dá de plantá é porque os
bicho come tudo, a capivara come
e não é pra matá né! Não pode, é
proibido... macaco come, istraga.
Tá cercando pra porco, pra ca-
pivara não comê, tudo de tela e
cercado. A plantação da cana é
de geração antiga. (D. Juvelina,
73 anos).

Segundo Guarim (2005), para a comunidade, a caça aos animais consistia também em um lazer. Sua prática foi uma atividade existente, predominantemente masculina, com uso de espingardas de espoletas. Diversos caçadores, às segundas-feiras, perseguiam antas e porcos selvagens, os quais, depois de abatidos, eram repartidos entre o grupo. Atualmente, não podem transgredir a Lei n. 9.605 de 12 de fevereiro de 1998, que dispõe sobre crimes ambientais, que na Seção I, - Dos Crimes contra a Fauna:

Art 29. Matar, perseguir, caçar, apanhar, utilizar espécimes da fauna silvestre, nativos ou em rota migratória, sem a devida permissão, licença ou autorização da autoridade competente, ou em desacordo com a obtida.

Na plantação não é utilizado nenhum tipo de agrotóxico para o crescimento da cana-de-açúcar. Depois de moída, seu bagaço é reaproveitado como adubo, sendo uma parte jogada na roça, e a outra utilizada para alimentar os animais. O corte da cana é feito no período 
matutino entre $6 \mathrm{~h}$ e $7 \mathrm{~h} 30$, devido a ser mais amena a temperatura. Ele é feito manualmente utilizando-se um facão de $0,5 \mathrm{~m}$ de comprimento.

A cana-de-açúcar cortada é arrumada em feixes, que são amarrados com as folhas da própria cana e transportados nas costas, até a moenda. Em cada carga transportada pelo Sr. Francisco, são levados de 10 a 14 feixes, contendo entre 15 a 20 canas-de-açúcar em cada um. Esse trabalho de colher a cana-de-açúcar começa um dia antes da produção, de modo que, no dia seguinte, o processamento de fabricação da rapadura comece bem cedo (3 horas da manhã).

Sr. Francisco, esposo de D. Juvelina, com a qual trabalha na produção de rapadura, falou sobre o tipo de cana-de-açúcar, a quantidade nas touceiras, nos feixes, e sobre os tratos culturais utilizados no canavial:

O canaviá... ele tem bastante cana, né! E o cacho não é muito grande, poca cana, 10 fexe, 12 fexe de cana pra moe, aí é sim um poco dum, oto poco doto, só uma filera, não é sim um canaviá aqui, outro lá, cana todo paranaense. Não aduba e nem num ara o canaviá, só memo natureza, nada de adubá, nem de ará, só corta e larga de mão dele, a palhada vira esterco. (Sr. Francisco - esposo, 73 anos).

\section{ENGENHO}

Na comunidade de Varginha, na época do auge dos engenhos, existiam muitos engenhos de produção de rapadura. Hoje em dia, porém, apenas o da família França está em plena atividade, sendo ainda mantida a tração animal (cavalo) para moenda (Figura 1B).

Na fala de D. Juvelina, percebeu-se a extinção de muitos engenhos que existiam na comunidade e a importância de se manter as formas de trabalho aprendidas:
Quando eu conhecia, tinha tanto engenho, tinha tanto engenho, quando eu conhecia...eu conheci tanto engenho só de madeira, aquele que tinha a moenda de madeira. Tudo nigocio de madeira, tocado a boi. Tinha engenho do seu Traira, tinha de Mané da Cruz, tinha de papai e muito mais, seu Alfredo, de tio Faustino, de tio Guilhermino... (D. Juvelina, 73 anos).

Sr. Francisco, esposo de D. Juvelina, relatou também com tristeza a extinção dos demais engenhos no local e em outras comunidades vizinhas, como Barranco Alto:
Naquela época era só engenho, cada canto, cada um moradô ti- nha um engenho. Praia do Poço, cada uma casa tinha um enge- nho... cabô tudo, não existi mais, Barranco Arto era só engenho... cabô tudo... ( Sr. Francisco-espo- so, 73 anos).

A estrutura do engenho é toda de madeira, aberta, para facilitar a saída da fumaça da fornalha, e sua cobertura é com telhas de amianto. Ele é constituído de uma moenda de ferro acionada por tração animal (cavalo), uma fornalha feita com barro, argila e tijolo, que funciona à lenha, um tacho de cobre, uma gamela/cocho de madeira utilizada para colocar o caldo para o batimento/esfriamento, uma mesa de madeira de 1,70m x 0,60m de largura, fôrmas de madeira, conchas de cabaça e espátulas de madeira.

Percebe-se um elo muito forte dessa população com o aprendizado repassado por seus antepassados. Siqueira, Costa e Carvalho (1989) corroboraram esse fato quando relataram que os engenhos à beira do rio Cuiabá eram construídos de madeira e sua força motriz era hidráulica ou de tração animal. Além disso, para os atuais rapadureiros, a permanência da atividade está atrelada ao não uso de energia elétrica que, por seu custo, inviabilizaria a produção. 
Observa-se que os engenhos tradicionais que ainda persistem e resistem no Brasil são heranças de antepassados, a exemplo dos engenhos de rapadura do município de Barbalha, CE. Eles são unidades antigas, compradas há várias décadas no início da fabricação do produto na região do Cariri, ou foram herdadas por filhos ou netos de algum proprietário que os adquiriu naquela época (PAIXÃO; SOUZA, 2013).

Dona Juvelina e seu esposo contam com ajuda de um neto para levar a cana cortada da plantação até a moenda. Já seus irmãos, Sr. Francisco, Sr. Brasilio e Sr. Antônio, fazem esse transporte da cana até a moenda sozinhos.

Nos meses de chuva, que no local se concentram de novembro a março, o engenho não funciona, pois o canavial alaga por estar próximo às margens do rio. Assim, como não é possível fazer a colheita da cana-de-açúcar, não há produção da rapadura. Além disso, ocorre a perda de parte da cana-de-açúcar plantada, que é reparada pelo plantio de novas mudas no período menos chuvoso, ou seja, é um período de renovação de parte do canavial.

A rapadura é feita de março a novembro, direto, mês intero, toda semana, toda semana tá moendo cana. (Sr. Francisco - esposo, 73 anos).

Ferreira (1999) explicou que o calendário agrícola na região ribeirinha é definido pelo vaivém das águas. O preparo da terra, o plantio e a colheita de cultivares obedecem rigorosamente ao ciclo das chuvas. O período de maior atividade na lavoura acontece entre abril e novembro, ou seja, o tempo da vazante, de seca e de início das chuvas.

Apesar do canavial alagar no período chuvoso por estar em uma parte baixa do terreno, o engenho, que fica na parte mais alta, não é atingido. O rio Cuiabá, a mata ciliar e o "baixio" (várzeas), na sua estrutura e função, oferecem serviços de abastecimento de nutriente, de água, de lenha e de combustível. Ferreira (2010) descreve os lugares usados pela comunidade ribeirinha da seguinte maneira:
A calha do rio é o serviço de pro- visão e cultura, ou seja, de água, lazer, turismo, beleza cênica, a mata ciliar, que é o ponto mais alto, faz serviço de regulação, ou seja, regula enchente, qualidade de água, faz a contenção dos bar- rancos, e regula o assoreamento e é onde está localizado a moradia, o quintal e o engenho, e a parte baixa ou baixio, é uma área de inundação livre, faz o serviço de provisão, de alimento para o gado, obtenção de lenha, remé- dios, iscas e matérias-primas para a rapadura.

\section{PRODUÇÃO DE RAPADURA}

Todo o conhecimento sobre a produção foi adquirido por meio do convívio com os familiares mais velhos. A colheita e produção no local são realizadas em sistema de revezamento entre as famílias, de acordo com a fala do Sr. Francisco que confirma tal atividade:

Amanhã é quarta né?! Quinta fera oto moe, sexta fera oto moe e sábado oto moe. (Sr. Francisco, 73 anos ).

Esse revezamento é visto como parte da transmissão e manutenção dos conhecimentos adquiridos, e conforme Guarim (2005), eles reconhecem a importância da transmissão desse conhecimento. Tedesco (2006) ressalta que as práticas artesanais são o fundamento da indústria doméstica no Brasil, em que as relações familiares se estendem ao mundo do trabalho.

D. Juvelina acrescenta que, quando estava no auge da produção de rapadura no local, havia uma competição saudável entre as famílias quando se tratava de quem produzia mais. Relatou também sobre a forma de transporte do produto, 
que ocorria em canoas pelo rio Cuiabá para ser comercializados na feira do Porto, em Cuiabá.

Os rapadureiro, um quiria fazê a coleita primero do que outro, pra falá que tô na frente... uma batida de rapadura aqui, lá na beira do rio tudo iscutava, olha fulano já tá na frente. Ai nóis aqui, o pessoal, parenti, ai trabalhava, trabalhava, trabalhava, enchia, canoa de rapadura, rumava caxa, caxa, caxa, caxa... até 1000 rapadura, ai colocava na canoa i levava lá no Porto pra vendê, vendia e trocava (D. Juvelina, 73 anos).

Diferente de Varginha, na comunidade ribeirinha de Bonsucesso, localizada em Várzea Grande, MT, apesar dos laços consanguíneos existentes entre os rapadureiros, cada família tem seu próprio engenho (TAVARES, 2011).

Quando o rapadureiro pega os feixes de cana-de-açúcar, trazidos anteriormente para o engenho, de modo a começar o processo de produção de rapadura, ele só para após concluídas todas as etapas. São elas: moagem, cozimento/ fervura, batimento, resfriamento e modelagem da rapadura.

A produção da rapadura começa, então, às 3 horas da manhã, à luz de vela e lanterna. A primeira etapa é o processo de moagem da cana-de-açúcar, que é feito por tração animal (cavalo) girando a moenda de ferro no sentido anti-horário. A duração do processo de moagem é em média de 4 horas, e termina entre 7 h e 7 h30 da manhã. Nele, o moedor é aquele que fica responsável por passar a cana-de-açúcar pela moenda, e o tangedor é aquele encarregado de tocar o cavalo, fazendo a moenda girar. Na observação in loco, o moedor e o tangedor eram, respectivamente, $\mathrm{Sr}$. Francisco e D. Juvelina (Figura 1B).

Alguns engenhos de cana-de-açúcar, puxados por bois, atravessam o tempo por passar de geração a geração sem quase nenhuma tecnologia científica. $O$ senso comum resiste aos avanços tecnológicos, como também observou Macedo (2008) em comunidades rurais em Senhor do Bonfim, BA.

O caldo extraído da moagem é passado por um coador de plástico, médio e simples, a fim de reter as impurezas. $\mathrm{O}$ caldo coado cai num recipiente de metal com capacidade mínima de 60 e máxima de 80 litros. O caldo, denominado garapa, é retirado com um balde de plástico, transportado e depositado no tacho de cobre com capacidade de 180 litros. O tacho, ao receber a garapa, já está colocado sobre a fornalha, devidamente aquecida com a queima da lenha (bagaço da cana e troncos de árvores).

Quando o caldo inicia o processo de cozimento/fervura até o ponto da rapadura, durando em média quatro horas, D. Juvelina e Sr. Francisco se revezam mexendo e retirando as impurezas (folhas e bagacilhos, que são fragmentos da cana-de-açúcar). Elas são descartadas com uma espécie de escumadeira, feita com cabo de bambu e metade de uma cabaça com furos pequenos (Figura 1C). Esse processo é feito de forma ininterrupta.

O produto já bem concentrado é transferido do tacho para um recipiente de madeira denominado cocho para iniciar o processo de batimento/mexedura com duração média de uma hora (Figura 1D). Dessa forma, o material perde calor e assim inicia o resfriamento. A massa é batida no cocho de madeira até ficar com um aspecto brilhante (Figura 1E). O produto resfriado é levado para a modelagem, sendo colocado em fôrmas de madeira de encaixe, que lembram um tijolo pelo formato retangular. O resultado é, então, a rapadura (Figura $1 F$ ). O término de toda a operação ocorre em torno das $12 \mathrm{~h}$ horas (meio dia). 

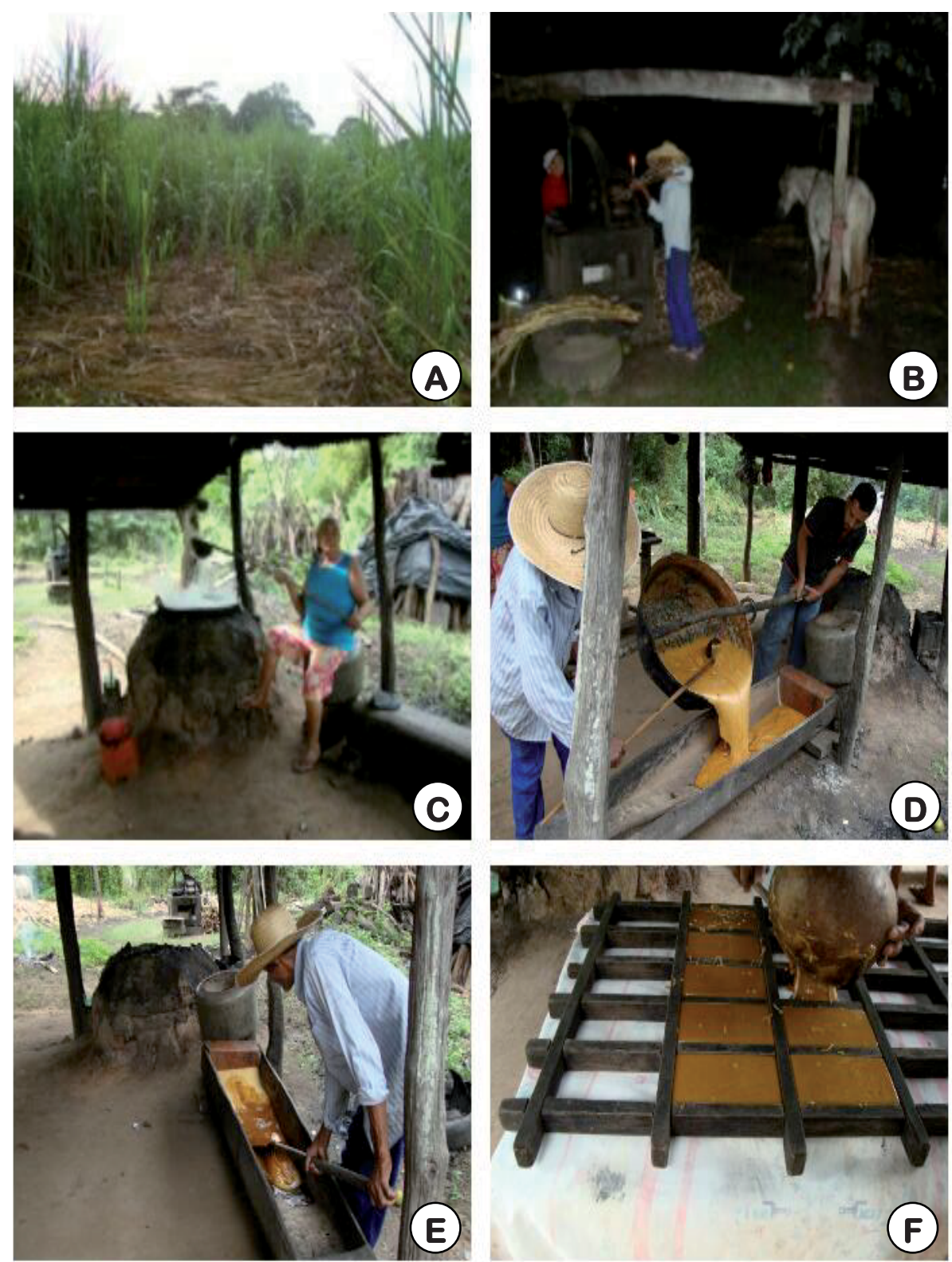

Figura 1 - Sequência de produção de rapadura na Comunidade de Varginha: A) Canavial; B) Moagem da cana por tração animal (cavalo); C) Cozimento/fervura até o ponto da rapadura; D) Transferência do caldo do tacho para o cocho; E) Batimento/mexedura do caldo concentrado; F) Modelagem da rapadura

Fonte: Fotos de Bruno Barbosa (2015)

São produzidas entre 23 a 25 rapaduras por dia, com validade estabelecida de um ano, de acordo com os rapadureiros. A embalagem é feita com sacolas plásticas, e as rapaduras são vendidas nos comércios da própria comunidade e feiras livres, por R \$ 7,00 cada uma.

Andrade (2007) observou na região de Pernambuco remanescentes de engenhos produzindo e comercializando mela- ço e rapadura. Com toda a dificuldade, há atualmente os que persistem em algumas regiões, concorrendo com a venda de produtos artesanais.

\subsection{Variedades de rapaduras}

No engenho da família França, há variedades no tipo de rapadura produzida. Alguns exemplos são: rapadura de 
mandioca, rapadura de banana, rapadura de mamão e rapadura tradicional (somente caldo da cana-de-açúcar). A rapadura tradicional é feita de segunda a sábado. As de banana, mamão e mandioca são feitas apenas por encomenda. D. Juvelina comenta:

A rapadura de mandioca, mamão e banana só quando encomenda, é trabalhoso pra fazer né! A mandioca é ralada, daqui a poquinho, seca, empenera, fica parecendo coco, mais também coloca bastante coco, canela, ela fica bem temperada, né. A rapadura de mamão ela fica bem seca, né,...ela é misturada no tacho, enquanto a de mandioca e banana é misturada no cocho. (D. Juvelina, 73 anos).

\subsection{Armazenamento do produto}

No Engenho dos França, segundo D. Juvelina, ela faz o armazenamento da rapadura separando o que será consumido pela família e o que será comercializado. Para o consumo da família, a rapadura permanece em temperatura ambiente, entre $25^{\circ}$ a $30^{\circ} \mathrm{C}$. Para revenda em comércios e feiras, as rapaduras ficam embaladas em sacolas plásticas e acondicionadas em caixa de papelão.

Observa-se, portanto, que o processo artesanal de produção da rapadura para os rapadureiros locais tem uma simbologia muito maior do que um valor mercadológico, pois está voltada para preservarem os hábitos, costumes da identidade cultural e social de seus antepassados, além de possibilitar complementação de renda.

Vender para o mercado não é o único fim. Parte considerável da produção é destinada ao consumo e às práticas sociais (festas, ritos, procissões, etc.), mantendo a unidade do grupo - ou seja, a sua produção é marcada por ritmo e lógica próprios. Desta forma, não se deve tentar subordinar os processos produtivos dessas comunidades tradicionais ao mercado ou qualquer outro patrão, pois elas são estruturadas com base nos princípios de autonomia e liberdade, que não combinam com a forma mercadológica imposta atualmente (MPMG, 2014).

\section{CONCLUSÕES}

Há apenas um engenho que funciona na comunidade de Varginha consorciado entre quatro irmãos que trabalham nele em sistema de rodízio durante a semana.

O manejo da cana-de-açúcar no Engenho dos França é feito de maneira artesanal com as mesmas técnicas utilizadas por seus antepassados, não sendo usado nenhum tipo de instrumento mecanizado e nenhum insumo agroquímico, apenas adubação pelos subprodutos: bagaço e palha.

A única energia usada no engenho é força motriz de um cavalo para a moagem de cana e dos próprios rapadureiros que fazem todo trabalho braçal em todo processo de produção da rapadura.

Há falta de interesse dos filhos e netos em dar continuidade ao processo da produção de rapadura, comprometendo assim a transmissão de conhecimento entre gerações.

\section{REFERÊNCIAS}

ABRAMOVAY, Ricardo. Ruralidade e desenvolvimento regional. Gazeta Mercantil, São Paulo, p. A-3, 15 abr. 2001. Disponível em: $<$ http://ricardoabramovay.com/ruralidadee-desenvolvimento-territorial/>. Acesso em: 4 mar. 2016.

ALBUQUERQUE, Ulysses Paulino; LUCENA, Reinaldo Farias P.; CUNHA, Luiz Vital F. Cruz (Org.). Métodos e técnicas na pesquisa etnobotânica. 2. ed. Recife, PE: NUPPEA, 2008. 323p.

AMOROZO, Maria Christina de Mello. Agricultura tradicional: espaços de resistência e o prazer de plantar. In: ALBUQUERQUE, U. P.; ALVES, A. G.; SILVA, A. C. B.; SILVA, 
V. A. (Org.). Atualidades em etnobotânica e etnoecologia. Recife, PE: SBEE, 2002. p. 123-131.

AMOROZO, Maria Christina de Mello; CULTRERA, Mirella; MIRANDA, Tatiana Mota. Ethnobotanical studies in smallscale agriculture: local knowledge and maintenance of agricultural diversity. In: ALBUQUERQUE, U. P.; RAMOS, M. A. (Ed.). Current Topics in Etnhobotany. Kerala, Índia: Research Signpost, 2008. p. 81- 99.

ANDRADE, Elias de Andrade; RIBEIRO, Marcilene. Um estudo toponímico de Bonsucesso e Pai André no Rio Cuiabá-MT. Revista ANPOLL, Florianópolis, SC, v. 1, n. 32, p. 171-203, 2012.

ANDRADE, Manoel Correia de Oliveira. Pernambuco e o trópico. Revista do IEB, São Paulo, n. 45, p. 11-20, 2007.

BERNARDES, Marcos Silveira; CÂMARA, Gil Miguel de Sousa. Cultura da cana-de-açúcar. Piracicaba, SP: ESALQ; Depto. de Produção Vegetal, 2001. 20 p.

BORBA, Maria Madalena Zocoller; BAZZO, Alex Marques. Estudo econômico do ciclo produtivo da cana-de-açúcar para reforma de canavial, em área de fornecedor do Estado de São Paulo. In: CONGRESSO DA SOCIEDADE BRASILEIRA DE ECONOMIA, ADMINISTRAÇÃOESOCIOLOGIA RURAL, 47., 26-30 jul. 2009, Porto Alegre, RS,. Anais... Porto Alegre: SOBER, 2009.

BRAIBANTE, Mara Elisa Fortes; PAZINATO, Maurícius Selvero; ROCHA, Thaís Rios; FRIEDRICH, Leandro da Silva; NARDY, Flávio Correia. A cana-de-açícar no Brasil sob um olhar químico e histórico. Química Nova na Escola, v. 35, n. 1, p. 3-10, 2013.

BRASIL. Lei n. 9.605, de 12 de fevereiro de 1998. Dispõe sobre as sanções penais e administrativas derivadas de condutas e atividades lesivas ao meio ambiente, e dá outras providências. Diário Oficial [da] República Federativa do Brasil, Brasília, DF, 12 fev. 1998.

. Lei n. 12.651, de 25 de maio de 2012, do Novo Código Florestal. Dispõe sobre a proteção da vegetação nativa; altera as Leis $\mathrm{n}^{\mathrm{o}} 6.938$, de 31 de agosto de $1981, \mathrm{n}^{\circ} 9.393$, de 19 de dezembro de 1996 e n $^{\circ} 11.428$, de 22 de dezembro de 2006; revoga as Leis $\mathrm{n}^{\circ} 4.771$, de 15 de setembro de 1965 e $n^{\circ} 7.754$, de 14 de abril de 1989 e a Medida Provisória $n^{\circ}$ 2.166-67, de 24 de agosto de 2001; e dá outras providências. Diário Oficial [da] República Federativa do Brasil, Brasília, DF, 25 maio 2012.

CLAVAL, Paul. O território na transição da pós-modernidade. Revista Géographies et Cultures, Paris, n. 20, 1996.

CONTERATO, Marcelo Antonio; RAMBO, Anelise Graciele; SCHNEIDER, Sergio; DEL RÉ, Megui. O índice de condições de vida (ICV) como instrumento para a gestão territorial do desenvolvimento rural. In: CONGRESSO DA SOBER, 50., Vitória. Anais... Vitória: SOBER, 2012.

DIEGUES, Antonio Carlos Sant'Ana (Org.). Os saberes tradicionais e a biodiversidade no Brasil. São Paulo: Nupaub-USP; ProbioMMA/CNPq, 2000. 211p.

DIEGUES, Antonio Carlos Sant'Ana. O mito moderno da natureza intocada. São Paulo: Hucitec, 1996.

FERREIRA, Maria Saleti Ferraz Dias. Lugar, recursos e saberes dos ribeirinhos do médio rio Cuiabá, Mato Grosso. 2010. 178 p. Tese (Doutorado em Ciências Biológicas) Universidade Federal de São Carlos (UFSCar), São Carlos, SP.

Comunidades ribeirinhas do médio Rio Cuiabá. In: FERREIRA, Maria Saletti Ferraz Dias (Org.). O Rio Cuiabá como subsídio para a educação ambiental. Cuiabá, MT: Editora da UFMT, 1999. p. 135-146.

FURTADO, Celso. Formação econômica do Brasil. 32. ed. São Paulo: Companhia Editora Nacional, 2003. 238p.

GUARIM, Vera Lúcia Monteiro dos Santos. A educação e a sustentabilidade ambiental em comunidades ribeirinhas de Mato Grosso, Brasil. Boletim do Museu Paraense Emílio Goeldi, Belém, PA, v. 1, n. 1, p. 7-44, 2005. (Série Ciências Humanas).

MACEDO, José Dionísio Borges. Rapadura: uma arte que atravessa os tempos: fonte de renda para a agricultura familiar de Senhor do Bonfim, Bahia. Bahia Agrícola, Salvador, BA, v. 8, n. 2, p. 35-38, nov. 2008.

MAITELLI, Gilda Tomasini. Uma abordagem tridimensional de clima urbano em área tropical continental: o exemplo de Cuiabá/MT. 1994. 
204p. Tese (Doutorado em Geografia) Universidade de São Paulo, São Paulo.

MAULE, Rodrigo Fernando; MAZZA, Jairo Antonio; MARTHA JR., Geraldo Bueno. Produtividade agrícola de cultivares de canade-açúcar em diferentes solos e épocas de colheita. Scientia Agricola, Piracicaba, SP, v. 58, n. 2, p. 295-301, abr./jun. 2001.

MENDES, Ana Beatriz Vianna; COSTA FILHO, Aderval; SANTOS, Ana Flávia Moreira. Tratados internacionais, populações tradicionais e diversidade biológica. Teoria e Sociedade, Número Especial: antropologias e arqueologias hoje, p. 235-249, 2015.

MINISTÉRIO PÚBLICO DE MINAS GERAIS (MPMG). Direitos dos povos e comunidades tradicionais. Coordenadoria de Inclusão e Mobilização Sociais. Superintendência de Comunicação Integrada. Belo Horizonte: MPMG, 2014. 52p. Disponível em: <http:// conflitosambientaismg.lcc.ufmg.br/wpcontent/uploads/2014/04/Cartilha-Povostradicionais.pdf>. Acesso em: 4 mar. 2016.

OLIVEIRA, Jailma Carvalho; NASCIMENTO, Ronaldo de Jesus; BRITTO, Waldenir Sidney Fagundes. Demonstração dos custos da cadeia produtiva da rapadura: estudo realizado no Vale do São Francisco. Custos e @gronegócio online, Recife, PE, v. 3, Edição Especial, p. 7999, maio 2007.

PAIXÃO, Denise de Lima; SOUZA, Eliane Pinheiro. A produção de rapadura no município de Barbalha: dificuldades e perspectivas. In: COLÓQUIO SOCIEDADE, POLÍTICAS PÚBLICAS, CULTURA E DESENVOLVIMENTO - CEURCA, 3., 6-8 nov. 2013., Crato, CE. Anais... Crato: URCA, 2013. p. 1536-1556.

PINTO, Carlos Benedito. Reflexos do processo de globalização no ritual de descida de mastro na festa do Senhor Bom Jesus da Varginha. In: SEMINÁRIO HUMANIDADES EM CONTEXTO:SABERESEINTERPRETAÇÕES, 11-14 nov. 2014, Cuiabá, MT. Anais... Cuiabá: UFMT, 2014. Disponível em: <http:// www.humanidadesemcontexto.com.br/
resources/anais/3/1415231358_ARQUIVO_ Humanidadessemcontexto_CarlosB_Pinto_ GT_HistePatrimonio_versaofinal-revisado. pdf>. Acesso em: 15 jul. 2015.

PÓVOAS, Lenine de Campos. O ciclo de açúcar e a política de Mato Grosso. 2. ed. Cuiabá, MT: IHGMT, 2000.

PRADO, Gustavo José Jordan; OSÓRIO, Patrícia Silva. Signos identitários na Comunidade de Varginha: construção narrativa de alteridade. In: CONGRESSO LUSO-AFRO-BRASILEIRO DE CIÊNCIAS SOCIAIS, 11., Salvador, BA, 7-10 ago. 2011. Anais... Salvador: UFBA, 2011.

RODRIGUES, Luciana Deotti. A cana-deaçúcar como matéria-prima para a produção de biocombustíveis: impactos ambientais e o zoneamento agroecológico como ferramenta para mitigação. 2010. 64 f. Trabalho de Conclusão de Curso (Especialização em Análise Ambiental) - Faculdade de Engenharia, Universidade Federal de Juiz de Fora, Juiz de Fora, MG.

SILVA, Carlos Magno; MARTA, José Manuel Carvalho. Caracterização de produção agrícola e os aspectos econômicos da canade-açúcar, mandioca e algodão arbóreo em Várzea Grande/MT. Revista Connection Line, Várzea Grande, MT, n. 6, p. 61-84, 2011.

SIQUEIRA, Elizabeth Madureira; COSTA, Lourença Alves; CARVALHO, Cathia Maria Coelho. O processo histórico de Mato Grosso. 3. ed. Cuiabá, MT: Guaicurus, 1989. 298p.

TAVARES, José Wilson. Várzea Grande: história e tradição. Cuiabá, MT: KCM, 2011. $158 \mathrm{p}$.

TEDESCO, João Carlos. O artesanato como expressão de um sistema de autarquia econômico-familiar no meio rural: subsídios para uma história econômica regional. Revista Teoria e Evidência Econômica, Passo Fundo, RS, v.14, Edição Especial, p. 241-246, 2006.

TOWNSEND, Claudio Ramalho. Recomendações técnicas para o cultivo da cana-de-açúcar forrageira em Rondônia. Embrapa, Rondônia, n. 21, p. 1-5, nov. 2000. 


\section{Sobre os autores:}

Bruno da Silva Barbosa: Tecnólogo em Gestão Ambiental pelo Instituto Federal de Educação, Ciências e Tecnologia de Mato Grosso (IFMT). E-mail: bruno-02@hotmail.com

Carla Maria Abido Valentini: Licenciatura em Ciências, Habilitação em Química, pela Universidade Federal de Mato Grosso (1988), mestrado em Física e Meio Ambiente pela Universidade Federal de Mato Grosso (2004) e doutorado em Agricultura Tropical pela Universidade Federal de Mato Grosso (2009). Professora do Instituto Federal de Educação, Ciências e Tecnologia de Mato Grosso (IFMT), campus Cuiabá-Bela Vista nas áreas de Química e Ciências Ambientais. E-mail: carla.valentini@blv.ifmt.edu.br

Rozilaine Aparecida Pelegrine Gomes de Faria: Possui graduação em Engenharia Sanitária pela Universidade Federal de Mato Grosso (1996), graduação em Química Licenciatura Plena pela Universidade Federal do Ceará (2001) mestrado em Química Orgânica pela Universidade Federal do Ceará (2003) e doutorado em Agricultura Tropical pela Universidade Federal de Mato Grosso (2009). Tem experiência na área de Química, com ênfase em Química dos Produtos Naturais, atuando principalmente nos seguintes temas: estudo de óleos voláteis, estudo de espécies de ocorrência do Cerrado para fins alimentares, aplicação de óleos essenciais e extrato de plantas em alimentos, compostos antioxidantes de interesse na área de alimentos. Tem interesse no conhecimento químico e desenvolvimento tecnológico envolvendo frutos de espécies do Cerrado, principalmente as espécies frutíferas nativas, entre as quais Brosimum gaudichaudii. É professora e orientadora do Mestrado em Ciências e Tecnologia de Alimentos na linha de pesquisa Qualidade de Alimentos do Instituto de Educação, Ciência e Tecnologia de Mato Grosso (IFMT), campus Cuiabá-Bela Vista. Participa no desenvolvimento de trabalhos acadêmicos envolvendo a área ambiental. E-mail: rozilaine.faria@blv.ifmt.edu.br 